\title{
How long will we live?
}

John Bongaarts

Population Council

Follow this and additional works at: https://knowledgecommons.popcouncil.org/departments_sbsr-pgy

Part of the Demography, Population, and Ecology Commons How does access to this work benefit you? Let us know!

\section{Recommended Citation}

Bongaarts, John. 2006. "How long will we live?" Policy Research Division Working Paper no. 215. New York: Population Council. Version of record: https://doi.org/10.1111/j.1728-4457.2006.00144.x 


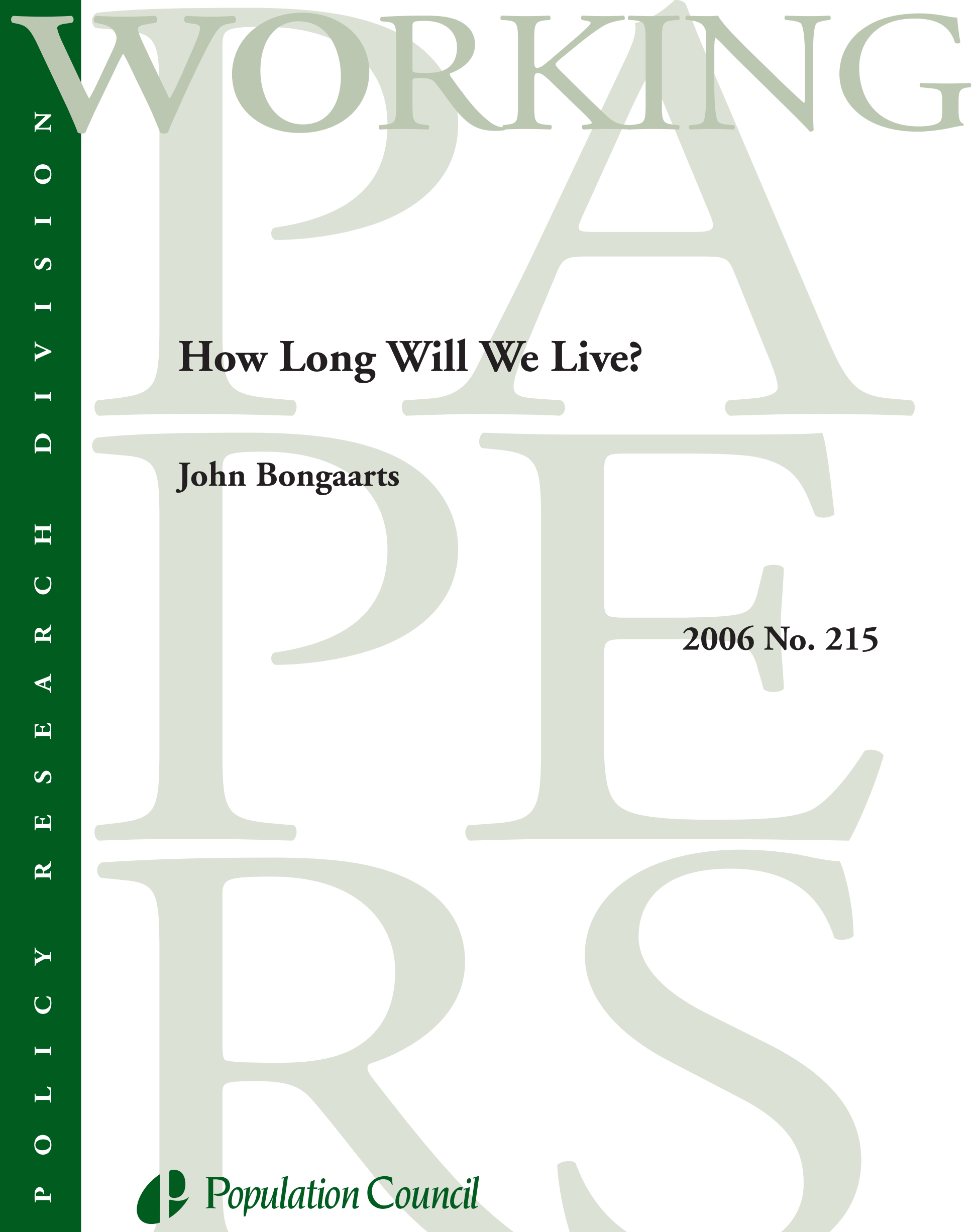




\section{(1) Population Council}

One Dag Hammarskjold Plaza

New York, New York 10017 USA

www.popcouncil.org

pubinfo@popcouncil.org

This material may not be reproduced without written permission from the author. For a list of Policy Research Division Working Papers, including those that are currently available for downloading in PDF format, see www.popcouncil.org/publications/wp/prd/rdwplist.html.

ISSN: $1554-8538$

(C) 2006 The Population Council, Inc. 


\title{
How Long Will We Live?
}

\author{
John Bongaarts
}

John Bongaarts is Vice President, Policy Research Division, Population Council, New York.

This research was funded in part through NIA grant no. R03 AG024083-01A1. Paul Demeny, Griffith Feeney, and Samuel Preston provided helpful comments on an earlier version of this paper. 


\begin{abstract}
Since 1800 life expectancy at birth has doubled from about 40 years to nearly 80 years in high-income countries. Pessimists expect these improvements to end soon because we are approaching biological limits to longevity, whereas optimists predict continued rapid improvements without limits. To shed light on this controversy, past trends in the juvenile, background, and senescent components of life expectancy are examined in 16 high-income countries. Large increases in conventional life expectancy before 1950 are found to be primarily attributable to reductions in juvenile and background mortality. After 1950 the rate of improvement in life expectancy slowed because declines in juvenile and background mortality slowed, but senescent mortality fell more rapidly than before, thus becoming the main cause of rising life expectancy at birth. The role of smoking in the past half-century is also quantified. In the future, background mortality and juvenile mortality will have little or no impact on longevity because they have reached very low levels. There is, however, no evidence of approaching limits and life expectancy will likely improve at a rate of approximately 1.5 years per decade owing to continued declines in senescent mortality.
\end{abstract}


One of the most notable achievements of modern societies is a large rise in human longevity. Since 1800 life expectancy at birth has doubled from about 40 years to nearly 80 years. Recent mortality trends are well established, but there is considerable disagreement among demographers and biologists about what lies ahead. Pessimists believe we are approaching limits to life expectancy, while optimists expect continued rapid improvements with no limits. Much is at stake: improvements in longevity are a key cause of skyrocketing costs of pensions and healthcare for the elderly.

After a brief review of the controversy about future trends, this study examines past trends in the components of life expectancy at birth. The projection of these components provides the basis for assessing plausible future trends in longevity. The focus throughout is on high-income countries with low levels of mortality.

\section{From PESSIMISM TO OPTIMISM}

Reliable historical estimates of mortality are available for a small number of countries. Figure 1a plots past estimates of life expectancy at birth for females in 16 highincome countries: Austria, Belgium, Canada, Denmark, England and Wales, Finland, France, Italy, Japan, Netherlands, New Zealand, Norway, Spain, Sweden, Switzerland, and the United States (Human Mortality Database 2005). ${ }^{1}$ The longest plotted time series start in 1850 and end in 2000 and the shortest are from 1950 to 2000 . Trends for male life expectancy at birth in Figure $1 \mathrm{~b}$ are broadly similar, although males live, on average, a few years less than females. All 16 countries experienced large increases in life expectancy. The only significant interruptions in this overall upward trend are attributable to the global influenza epidemic in 1918-19 and two World Wars. Differences between these countries have narrowed considerably over time, leaving most countries today with life expectancies close to the average for the group, regardless of historical patterns. In recent decades, countries have moved in tandem within a narrow range to reach an average in 2000 of 81.5 years for females and 75.8 years for males. This remarkable convergence is presumably due to a reduction in disparities among countries in standards of living, nutrition, and public health measures and increasingly rapid diffusion of advances in medical treatment, drug therapy, and life style among countries (Riley 2001). Other notable features evident in Figure 1 are the less rapid pace of improvement in female life expectancy in recent decades than in the century before the 1950s and the stall in male life expectancy in the 1950s and 1960s. The future implications of these recent trends are the subject of a contentious debate.

Pessimists believe that future life expectancy has an upper limit of about 85 years and they provide biological and demographic evidence in support of this view (Fries 1980; Olshansky, Carnes, and Cassel 1990). The biological argument considers mortality after the reproductive ages to lie beyond the reach of Darwinian forces of natural selection. As a result, an "intrinsic" biologically determined age pattern of senescent mortality is said to exist, which rises steeply with age after about age 30 in humans. This pattern is "expected to remain invariant unless the genome itself is modified" (Carnes, Olshansky, and Grahn 1996: 252). The pessimists' demographic argument claims that 
improvements in life expectancy at birth can only result from declines in "premature" mortality among children and young adults. In contrast, senescent mortality at older ages is considered largely immutable, because at the end of the natural life span "everything comes apart at once and repair is impossible" (Fries 1980: 135).

Up to the 1980s this pessimistic perspective was accepted by many demographers. For example, Bourgeois-Pichat (1978) proposed "biological" limits for life expectancy of 80.3 years for females and 73.8 years for males. Population projections prepared by the United Nations at various times from the 1950s to the 1980s included a maximum. This pessimism led to the consistent underestimation of future improvements in longevity in projections made before the 1990s (Keilman 1997).

Several developments during the 1990s led to the demise of this pessimism. First, most proposed past limits to life expectancy were exceeded, often soon after they were introduced (Oeppen and Vaupel 2002). This continuous need for an upward revision of supposedly fixed limits is evident in the past record of United Nations projections, which raised their maximum life expectancy several times before the mid-1980s. The more recent UN projections have abandoned the practice of imposing limits. Second, agespecific death rates at the oldest ages show no evidence of leveling off. On the contrary, these rates exhibit steady declines (Lee and Carter 1992; Kannisto et al. 1994). Third, the pace of improvement in old-age mortality shows no relationship to the level of old-age mortality (Wilmoth 1997). If limits exist, one would expect countries close to the limit to experience smaller and slower improvements than countries that are farther from the limit. Finally, the claim that mortality at the oldest ages is not subject to the forces of natural selection is being questioned (Lee 2003). Moreover, it is doubtful whether a biological argument can contribute insight into the potential future impact of medical interventions, even if it explains the exponential rise with age in post-reproductive-age mortality.

In their recent writings, the pessimists seem to have made a concession. Instead of being immutable, the limits to life span are now referred to as "a mortality schedule that, in the absence of medical interventions, cannot further be reduced" (Olshansky, Carnes, and Brody 2002: 505; italics added). Any such improvements "manufacture survival time by saving the lives of people who would otherwise die" (ibid.). This language represents a significant change in position, or at least in the position as interpreted by many readers of the earlier work of Olshansky and his colleagues. It is quite possible, indeed likely, that most improvements in mortality at older ages in the future will be "manufactured" through medical interventions, but if that is the case the net result will still be a life expectancy beyond the proposed limits of about 85 years. As noted by Wilmoth (2001), the difference of opinion between Olshansky and Carnes and other demographers about likely future trends in life expectancy now appears to be smaller than is widely presumed.

A recent panel report of the National Research Council concludes that if any limits exist, they are far above current levels, and that projections therefore should not impose ceilings (National Research Council 2000). This view is now widely held in the demographic community, and the focus of debate has shifted from the limits to life expectancy to the size of future increases in life expectancy. There is, however, no 
agreement about most plausible future trends. Optimists such as Fogel and Costa (1997) document long-range improvements in human physiology (e.g., body size; durability of vital organ systems) as a result of increased human control of the environment, and they expect continued rapid improvements in longevity during the twenty-first century. Manton, Stallard, and Tolley (1991) also anticipate much higher levels of life expectancy in the future owing to the development of interventions to address chronic diseases at advanced ages. Oeppen and Vaupel (2002) observe that best-practice life expectancy has increased by 2.5 years per decade for the past century and a half, and they conclude that a "reasonable scenario" would be for this trend to continue. This view is not shared by most national and international agencies that are responsible for preparing official country projections. Their projections are considerably more conservative even if they do not impose limits. For example, United Nations projections for the next half century made in 2004 (without a life span limit) expect female life expectancy in the United States to increase at a rate of 1.1 years per decade (United Nations 2005). Similarly, the US Social Security Administration assumes a rise in life expectancy of only 0.8 years per decade over the same period (Board of Trustees OASDI 2005). These projected rates of future improvement are less than half the rate considered reasonable by Oeppen and Vaupel (2002). The question of what lies ahead remains unsettled.

\section{COMPONENTS OF LIFE EXPECTANCY LEVELS AND TRENDS}

Before discussing the future prospects for life expectancy it is necessary to interpret past trends. For this purpose I propose a procedure for decomposing life expectancy. This decomposition divides the level of life expectancy at a given point in time into three components, which quantify the roles of juvenile, background, and senescent mortality.

- Juvenile mortality. Past increases in life expectancy at birth (denoted $L E$ ) are in part due to declines in mortality at the youngest ages. For present purposes all mortality under age 25 will be considered "juvenile". ${ }^{2}$ To quantify the role of juvenile mortality, I calculate a variant of the conventional life expectancy at birth. This variant, called "life expectancy without juvenile mortality" (denoted $L E_{J}$ ), equals the average age at death for a newborn as calculated with a mortality life table in which all newborns are assumed to survive to age 25 . In more conventional demographic terminology $L E_{J}$ equals life expectancy at age 25 plus 25 . It is a measure of adult mortality over age 25 .

-Background mortality. Past studies of age patterns of adult mortality have often distinguished between background and senescent mortality (Carnes, Olshansky, and Grahn 1996; Gavrilov and Gavrilova 1991; Horiuchi and Wilmoth 1998; Makeham 1860). The distinction between these two components of adult mortality is useful for describing age patterns of death rates, and models using it provide an extremely good fit to empirical data (Bongaarts 2005; Thatcher 1999). The risks of some causes of death (e.g., cardiovascular disease and cancer) rise strongly with age and therefore are considered part of senescent mortality. Other causes of death do not show a strong age pattern (e.g., accidents, violence, and some infectious diseases) and they are considered 
part of background mortality, which is assumed to be age invariant in the models. A complete mapping of causes of death to the background and senescent components is difficult and is not attempted here. Instead, background mortality is estimated with an empirical method proposed by Bongaarts (2005) and summarized in the Appendix. As shown next, this estimate permits the calculation of the contribution of background mortality to levels and trends in life expectancy.

- Senescent mortality. Senescent mortality rises rapidly with age owing to the deterioration of physiological processes at the cellular and systemic levels. Estimates of senescent mortality by age are obtained by subtracting background mortality from the observed total death rate at each age. To summarize the resulting age pattern of senescent mortality, I introduce a third longevity measure called "senescent life expectancy." Senescent life expectancy (denoted $L E_{S}$ ) is defined as the mean age at death for a newborn, on the assumption that all newborns survive to age 25 and are not subject to background mortality. That is, $L E_{S}$ equals the life expectancy obtained with a conventional life table in which senescent mortality is the only cause of death.

Once estimates of these three longevity measures- $L E, L E_{J}$, and $L E_{S}$-are available, the roles of juvenile and background mortality are readily calculated. The effect of juvenile mortality on life expectancy (denoted $J$ ) is estimated as the difference between $L E_{J}$ and $L E$ :

$$
J=L E_{J}-L E
$$

and the role of background mortality is quantified as the difference between senescent life expectancy and life expectancy without juvenile mortality:

$$
B=L E_{S}-L E_{J}
$$

These measures lead to a simple equation for decomposing life expectancy:

$$
L E=L E_{S}-B-J
$$

The conventional life expectancy at any point in time equals senescent life expectancy minus the longevity-reducing effects of background and juvenile mortality.

This equation for the components of the level of life expectancy yields a similar decomposition for the change or trend in life expectancy at birth between two successive points in time. The change in life expectancy at birth $(\Delta L E)$ equals the rise in senescent life expectancy $\left(\Delta L E_{S}\right)$ plus the background mortality effect $(\Delta B)$ plus the juvenile mortality effect $(\Delta J)$ :

$$
\Delta L E=\Delta L E_{S}+\Delta B+\Delta J
$$

In this decomposition model, changes in the components between times $t_{1}$ and $t_{2}$ are estimated as $\Delta L E=L E\left(t_{2}\right)-L E\left(t_{1}\right), \Delta L E_{S}=L E_{S}\left(t_{2}\right)-L E_{S}\left(t_{1}\right), \Delta B=B\left(t_{1}\right)-B\left(t_{2}\right)$ and $\Delta J=J\left(t_{1}\right)-J\left(t_{2}\right)$. 


\section{DECOMPOSITION RESULTS: 1850-2000}

The longevity measures $L E, L E_{J}$, and $L E_{S}$ were calculated for each of the 16 countries for all available years, separately for females and males. Only a partial summary of the voluminous results can be provided here. The focus is on average trends for females in the five countries with records from 1850 to 2000: Denmark, England and Wales, Netherlands, Norway, and Sweden. Results for males are included in the figures but are not discussed in detail.

Figure 2a plots average estimates for females for this subset of five countries from 1850 to 2000, and Table 1 presents results for selected years. Over this period the following changes occurred:

- Life expectancy $(L E)$ increased from 45.7 years to 80.7 years $(+35)$

- Life expectancy without juvenile mortality $\left(L E_{J}\right)$ increased from 63.9 years to 81.4 years $(+17.5)$

- Senescent life expectancy $\left(L E_{S}\right)$ increased from 72.3 years to 81.7 years $(+9.4)$

In 1850 senescent life expectancy exceeded life expectancy at birth by 26.6 years $(72.3$ vs. 45.7), but by 2000 the difference had narrowed to just 1 year (81.7 vs. 80.7). The cause of this convergence is a large secular decline of juvenile and background mortality to very low levels. As shown in Figures 3 and 4, the effect of juvenile mortality declined from 18.2 years to 0.6 years $(-17.5)$, and the background mortality effect declined from 8.4 years to just 0.3 years $(-8.1)$.

Life expectancy at birth rose by 35 years between 1850 and 2000. This change can be expressed as the sum of the effects of changes in senescent life expectancy $\left(\triangle L E_{S}\right.$ $=9.4$ years $)$, background mortality $(\Delta B=8.1$ years $)$, and juvenile mortality $(\Delta J=17.5$ years): $35=9.4+8.1+17.5$. These effects changed considerably over time. Figure 5 presents a decomposition of trends for the periods 1850-1900, 1900-1950, and 19502000. Life expectancy at birth rose more rapidly between 1900 and $1950(+20.1$ years) than in the period $1850-1900(+6.4$ years) or $1950-2000$ ( +8.5 years). The large increase in conventional life expectancy before 1950 was primarily attributable to reductions in juvenile and background mortality. After 1950 the rate of improvement in life expectancy slowed because improvements in juvenile and background mortality slowed, but the pace of increase in senescent life expectancy rose. Between 1950 and 2000, the rise in female senescent life expectancy of 5.6 years became the dominant cause of the rise in life expectancy of 8.5 years.

A plausible explanation for the recent acceleration of the improvement in senescent life expectancy is that medical treatment became more effective around the middle of the twentieth century with the widespread use of antibiotics and the ability to treat cardiovascular and other chronic diseases (Costa 2005; Crimmins 1981; Riley 2001). Apparently, the factors that brought about massive declines in juvenile and background mortality before 1950 (i.e., improvements in standards of living and nutrition, and the introduction of public health measures) had little impact on senescent mortality. 


\section{GENDER DIFFERENCES IN SENESCENT LIFE EXPECTANCY AND THE ROLE OF SMOKING: 1950-2000}

Aside from the well-established fact that longevity is slightly shorter for males than for females, the long-range trend in senescent life expectancy for males is broadly similar to that for females. As was the case for females, male $L E_{S}$ increased little before 1950 but accelerated in recent decades (see Figure 2 and Table 1). The main difference between sexes is that male $L E_{S}$ stagnated during the 1950 s and 1960 s while improvement continued for females. This finding requires a brief exploration because it has implications for the projection of life expectancy by sex.

Smoking behavior provides a plausible partial explanation for the stalling of male life expectancy and the divergence of trends in male and female life expectancy in the 1950s and 1960s (Gjonca et al. 2005; Pampel 2002; Peto et al. 1994; Valkonen and von Poppel 1997). Cigarette smoking rose substantially in the first half of the twentieth century, and the resulting excess mortality was observed after a delay of a few decades. Figure 6 plots the proportion of all deaths attributed to smoking by sex for the developed world (Peto et al. 2005). This proportion is much higher for males than for females, reflecting the earlier adoption and higher prevalence of smoking among males. The smoking impact among males peaked in 1990 at 25 percent of all deaths. The subsequent decline is the delayed mortality response to the decline in smoking among males that followed the confirmation in the 1960s of the link between smoking and lung cancer. In contrast, the female proportion of deaths due to smoking rises steadily. As a result, smoking appears to be the main reason for the widening of sex differentials in mortality in the middle of the twentieth century and for the subsequent narrowing of this differential in recent years (Gjonca et al. 2005; Pampel 2002).

The impact of smoking on life expectancy can be estimated by using the age- and sex-specific proportion of deaths attributed to smoking from Peto et al. (2005). The removal of smoking mortality from the life table calculations results in a variant of senescent life expectancy that I call "senescent life expectancy without smoking" and denote $L E_{N S}$ (see Appendix for details). The difference between senescent life expectancy with and without smoking equals the smoking effect, $S$ :

$$
S=L E_{N S}-L E_{S}
$$

Figure 7 and Table 2 present average values of $L E_{N S}$ and $L E_{S}$ and the smoking effects for all 16 countries used in this study for males and females. The smoking effect varies over time and differs between sexes. For males it averages 1.1 years in 1950, rises to a peak of 3.0 years in 1980 and 1985 , and declines slightly to 2.4 years in 2000 . For females the effect is very small in 1950 but rises steadily to 1.0 year by 2000 . Without the smoking effect males still have lower life expectancy than females but the difference has narrowed at every point in time. Country-specific estimates of $L E_{N S}$ and $S$ in 1950 and 2000 are presented in Table 3. These results are not discussed here but Peto et al. (2005) review smoking mortality levels and trends in developed countries. 
The removal of the smoking effect changes the trend in average senescent life expectancy between 1950 and 2000. Without smoking, $L E_{N S}$ rises by an average of 6.9 years for males (from 73.3 to 80.2 years) and by a slightly higher amount, 8.2 years, for females (from 75.6 to 83.8 years). These increases are larger than those that occur with smoking $\left(L E_{S}\right)$ for females (8.2 instead of 7.2 years) and in particular for males (6.9 instead of 5.6 years). The trend in male senescent life expectancy without smoking is more linear than with smoking, and it is broadly similar to that for females. The stall in the 1950 s and 1960 s in male $L E_{S}$ has disappeared.

Figure 8 compares male and female senescent life expectancy without smoking for each of the 16 high-income countries from 1950 to 2000. In contrast to trends in life expectancy, these trends are roughly linear for both sexes. Differences among countries are remarkably small: the standard deviation for both males and females is just 1.0 year in 2000. The steady pace of increase and the similarity of trends for males and females make this longevity indicator more suitable than conventional life expectancy for making projections.

\section{IMPLICATIONS FOR FUTURE LIFE EXPECTANCY}

Existing methods for projecting future life expectancy rely wholly or in part on extrapolation of past trends in mortality rates, longevity measures, or parameters in mortality models (Keyfitz 1991; Lee 1998; Pollard 1987; Tabeau, Jeths, and Heathcote 2001). This general approach is also used in a new method for projecting life expectancy proposed below. Based on the preceding analysis of the components of life expectancy, this method considers senescent life expectancy without smoking, $L E_{N S}$, to be the main driver of future life expectancy at birth, and considers the effects of background, juvenile, and smoking mortality to be secondary factors. This approach is proposed for highincome countries with low mortality because background and juvenile have reached such low levels that any further changes in them will have little impact on future life expectancy. As a result, nearly all future improvement in life expectancy at birth will have to come from improvements in senescent longevity. In addition, the smoking effect should be taken into account to ensure more reliable forecasts, because the rise in smoking mortality in recent decades has obscured the underlying trends in improvements in senescent mortality.

The preparation of a projection of life expectancy at birth based on past trends in $L E_{N S}$ involves several steps. ${ }^{3}$

1) Calculation of past trends in $L E_{N S}$ for a period of at least several decades using the methods described above. Estimates can be made separately for females and males or for the male and female population combined. This step is illustrated in Table 3, which gives estimates of $L E_{N S}$ in 1950 and 2000 for 16 countries.

2) Extrapolation of $L E_{N S}$ for the desired duration of the projection. A linear extrapolation of the pace observed in the past may be acceptable in many countries, in particular if past trends in $L E_{N S}$ are more or less linear. This extrapolation can be based on country-specific trends or on the average of past trends in all 16 countries. ${ }^{4}$ 
3) Projection of effects of juvenile, background, and smoking mortality $(J, B$, and $S)$. Linear extrapolation of past trends in these components is unlikely to yield satisfactory results and the analyst will have to use nonlinear methods. These are not discussed here, but in countries where $J$ and $B$ have reached very low levels, holding them constant at 2000 levels may provide a reasonable approximation.

4) Projection of life expectancy at birth, $L E$, by subtracting the projected values of $J, B$, and $S$ from the projected $L E_{N S}$ for any future year:

$$
L E=L E_{N S}-J-B-S
$$

No attempt is made here to make complete projections for each of the four factors- $L E_{N S}, J, B$, and $S$-that determine future trends in $L E$. However, it is useful to compare existing projections of life expectancy at birth with the future trend implied by a projection in which only the dominant component $L E_{N S}$ is assumed to change. In this comparison $J, B$, and $S$ are held constant at levels in 2000, so that the pace of increase in projected life expectancy in future years is the same as the past pace of increase in senescent life expectancy without smoking. ${ }^{5}$ The resulting projections are probably conservative because in most countries some further declines in background and juvenile mortality are likely, and ongoing declines in smoking will bring future declines in smoking mortality. To simplify matters further, I assume in the comparisons presented below that the rate of increase in senescent life expectancy without smoking is equal to the average pace for $L E_{N S}$ for males and females in all 16 countries from 1950 to 2000 (i.e., 0.15 years per year or 7.5 years for the period 2000-2050). This implies that increases in longevity are driven by improvements in medical technology or behavior that will have the same impact in all countries, and any country-specific deviations from this common trend that may occur are considered random and therefore unpredictable. This approach is rarely used by demographers, because it disregards country- and sex-specific past trends. It may nevertheless turn out to be as good as or better than the conventional country- and sex-specific projections, particularly in countries whose past mortality improvements have been much higher or lower than average. This approach ensures that differences between countries or differences between sexes remain at 2000 levels, thus avoiding the implausible divergence (or convergence and crossover) between countries or sexes that can result in the long run from more conventional projections.

To illustrate, I compared life expectancy projections for females in the United States from 2000 to 2050. Between 1950 and 2000 life expectancy rose from 71.1 to 79.5 years. As shown in Figure 9, the new projection with constant values for $J, B$, and $S$ expects female life expectancy in the United States to rise to 87.0 years in 2050 (to 81.6 for males). This result is several years lower than the optimistic Oeppen-Vaupel projection, which gives a life expectancy of 91.6 for females in 2050 (assuming a rate of improvement of 0.25 years per year). The main reason for this difference is that Oeppen and Vaupel make no allowance for the future disappearance of the effect of declining juvenile and background mortality. Figure 9 also includes the most recent projection by the US Social Security Administration, which assumes life expectancy at birth in 2050 to 
rise to 83.2 for females and 79.4 for males (Board of Trustees OASDI 2005). This official projection is based on complex assumptions about and extrapolations of age-, sex-, and cause-specific death rates. The result is substantially lower longevity in the future than is projected here with the new method. Other researchers have also concluded that the US Social Security Administration underestimates future improvements in life expectancy (Lee 2000; Tuljapurkar, Li, and Boe 2000). ${ }^{6}$ In fact, a technical advisory panel to the Social Security Advisory Board recommends an upward revision of these official projections (Technical Panel on Assumptions and Methods 2003). Any upward revision would, of course, imply a higher future deficit of the US Social Security and Medicare programs.

I prepared similar projections with constant values for $J, B$, and $S$ for each of the other 15 low-mortality countries. The results of this exercise are summarized in Table 4. On average, female life expectancy is expected to rise from 81.5 to 89.1 years between 2000 and 2050 (from 75.8 to 83.3 years for males). The most recent UN projections for each country are presented in the last column of Table 4 . They average 87.5 for females and 82.2 for males in 2050 , which is 1.6 years lower than the new projection for females and 1.1 years lower for males. The main reason for this difference is that the average rate of future improvement is assumed to be 0.15 years per year while the UN assumes this pace to converge to around 0.11 years per year by the middle of this century. ${ }^{7}$

\section{CONCLUSION}

Life expectancy has risen in the past as a result of declines in juvenile, background, and senescent mortality. The premise of this study is that projections of life expectancy will be more accurate if they take into account past trends in these components and in smoking mortality. The new projection approach proposed here removes the effects of juvenile, background, and smoking mortality from past longevity estimates before extrapolating future trends. The removal of these factors reveals the fundamental underlying trend in senescent life expectancy, and this trend is assumed to be the key driver of future life expectancy trends.

The steady upward trend in senescent life expectancy in recent decades confirms the optimists' view that there is no evidence of approaching limits to longevity. However, the pace of this improvement has been below the optimistic estimate of 0.25 years per year by Oeppen and Vaupel (2002). After trends in juvenile, background, and smoking mortality are removed, the average rate of increase in senescent life expectancy over the past 50 years was 0.15 years per year (male-female average). Because senescent life expectancy has increased almost linearly since 1950, it is plausible to assume that this trend will continue for a few more decades. This implies that life expectancy is likely to increase by an average of about 7.5 years over the next 50 years, plus any-probably minor - effects of further declines in juvenile, background, and smoking mortality. There is no reason to believe that advances in biotechnology, preventive and curative medicine,

and drug treatment will be less effective in reducing senescent mortality in the future than in the past. 
The pessimists are correct in their claim that past life expectancy improvements were largely driven by non-repeatable reductions in mortality among children and young adults. Declines in juvenile and background mortality have indeed reached such low levels that they can make little or no contribution to further increases in longevity. This is one of the main reasons why life expectancy at birth rose more slowly in recent decades than in the century before 1950. Nevertheless, declines in senescent mortality, which were minimal before 1950, have been substantial since then, and they should result in continuous advances in life expectancy in future decades.

The preceding analysis suggests that longevity improvements will be larger and population aging will be more rapid than many governments of high-income countries expect. 


\section{APPENDIX}

\section{a) Estimation of background mortality}

The conventional method for estimating background mortality involves two steps. The first is the specification of a model for the force of mortality by age for adults. One of the parameters in this model should be the level of background mortality, which is assumed age invariant. For example, Gavrilov and Gavrilova (1991) use a MakehamGompertz model and Horiuchi and Wilmoth (1998), Thatcher (1999), Thatcher, Kannisto, and Vaupel (1998), and Bongaarts (2005) use logistic models to which a Makeham parameter for background mortality is added. The latter model can be summarized as:

$$
\mu(a)=\frac{\alpha e^{\beta a}}{1+\alpha e^{\beta a}}+\gamma
$$

where $\mu(a)$ denotes the force of mortality at age $a$. This model has three parameters: $\alpha$ varies with the level of mortality, $\beta$ measures the rate of increase in mortality with age, and $\gamma$ equals background mortality.

The second step is to fit the model to the logarithm of the observed force of mortality by age, which yields estimates for the three model parameters, including the level of background mortality. The fitting procedure is repeated for each year and separately for females and males for each population, yielding time series of background mortality $\gamma(t)$. This method has provided a good fit to empirical data for ages 25-109 with $R^{2} \approx 0.999$ in developed countries between 1950 and 2000 (Bongaarts 2005).

\section{b) Estimation of senescent life expectancy}

To estimate senescent mortality by age, $\mu_{S}(a, t)$, background mortality $\gamma(t)$ is subtracted from observed mortality rates:

$$
\mu_{S}(a, t)=\mu(a, t)-\gamma(a, t)
$$

for ages above $25\left(\mu_{S}(a, t)=0\right.$ for $\left.a<25\right)$. These estimates of senescent mortality by age are then used in a life table to estimate senescent life expectancy:

$$
L E_{S}(t)=25+\int_{25}^{\infty} e^{-\int_{25}^{x} \mu(a, t)-\gamma(t) d a} d x
$$

\section{c) Estimation of smoking effect}

Let $s(a, t)$ be the proportion of deaths attributed to smoking at age $a$ and time $t$. The senescent force of mortality in the absence of smoking $\mu_{N S}(t)$ is estimated from the senescent force of mortality with smoking $\mu_{s}(t)$ as

$$
\mu_{N S}(a, t)=(1-s(a, t)) \mu_{S}(a, t)
$$


Peto et al. (2005) provides estimates of $s(a, t)$ for males and females in most developed countries at five-year intervals from 1950 to 2000 for three age groups: 0-34, 35-69, and 70+. These updated estimates are based on a method developed in Peto et al. (1992, 1994), which was designed to produce conservative results. If actual smoking mortality turns out to be higher than these conservative estimates indicate, then senescent mortality without smoking is higher and more linear than suggested in Figures 7 and 8 and Table 3. There is considerable uncertainty regarding the exact mortality risk associated with smoking. New studies continue to examine this issue with improved research designs (Preston and Wang 2006; Rogers et al. 2005; Taylor et al. 2002; Thun et al. 1998).

\section{NOTES}

1 This database also provides mortality estimates for a number of Eastern Europe countries, but they are not included in this study because this region has experienced recent fluctuations in mortality from extraordinary social, economic, and political changes. West Germany was also excluded because its time series starts in 1956. Estimates for the United States before 1959 are taken from the Berkeley Mortality Database. In a few countries, estimates for 2000 were taken from OECD (2005) because the database information ended in 1999 or 1998.

2 The selection of age 25 as the upper age for this component ensures that juvenile mortality includes the slightly elevated mortality observed in the late teens and early 20 s, much of which is attributable to accidents and violence.

3 The discussion here focuses on the projection of life expectancy at birth. In many practical applications, a projection of the distribution of deaths by age is required. Such a distribution can be obtained from model life tables, which is the procedure used by the UN (2005). An alternative approach relies on the finding that the distribution of senescent deaths by age retains its shape as life expectancy rises (see Bongaarts 2005 for details).

4 The "endpoint" method for projection is used; see Wilmoth (2005) for a discussion of advantages and disadvantages of this method.

5 This assumption implies a linear trend in life expectancy in the future. Olshansky and Carnes (2001) and Olshansky et al. 2005 criticize projections that assume such a linear trend. In the past, long-range trends in life expectancy in lowmortality countries have indeed not been linear, as is clear from Figure 1. White (2002) shows that trends in recent decades have been nearly linear for both sexes combined, but these trends will likely not continue because the contributions from declines in juvenile and background mortality cannot be repeated. The projection proposed here removes these confounding effects. A linear increase in life expectancy is associated with a geometric decline in age-specific death rates if mortality follows a Gompertz pattern (Vaupel 1986). 
6 Tuljapurkar, Li, and Boe (2000) project US life expectancy for both sexes combined to reach 82.9 years in 2050 using a variant of a method proposed by Lee and Carter (1992). This compares to male-female averages of 84.3 years for the new method proposed here. Projections of male-female averages of life expectancy at birth to 2050 for six other countries by Tuljapurkar, Li, and Boe (2000) are Japan (90.91), France (87.01), Italy (86.26), Canada (85.26), Britain (83.79), and Germany (83.12). These projections extrapolate trends within countries and are therefore different from the projections presented here, which assume the same future pace of improvement for all countries.

7 In United Nations projections for low-mortality countries, the pace of improvement varies over time and converges to a fixed rate, which can vary among countries (United Nations 2005).

\section{REFERENCES}

Berkeley Mortality Database. 2002. Data downloaded from www.demog.Berkeley.edu in January 2002.

Board of Trustees of OASDI Trust Funds. 2005. The 2005 Annual Report of the Board of Trustees of the Federal Old-Age and Survivors Insurance and Disability Insurance Trust Funds. Washington, DC: US Government Printing Office.

Bongaarts, John. 2005. "Long-range trends in adult mortality: Models and projection methods," Demography 42(1): 23-49.

Bourgeois-Pichat, Jean. 1978. "Future outlook for mortality decline in the world," Population Bulletin of the United Nations 11: 12-41.

Carnes, Bruce A., S. Jay Olshansky, and Douglas Grahn. 1996. "Continuing the search for a law of mortality," Population and Development Review 22(2): 231-264.

Costa, Dora, L. 2005. "Causes of improving health and longevity at older ages: A review of the explanations," Genus 61(1): 21-38.

Crimmins, Eileen M. 1981. "The changing pattern of American mortality decline, 194077, and its implications for the future," Population and Development Review 7(2): 229-254.

Fogel, Robert W. and Dora L. Costa. 1997. "A theory of technophysio evolution, with some implications for forecasting population, health care costs, and pension costs," Demography 34 (1): 49-66. 
Fries, James F. 1980. "Aging, natural death, and the compression of morbidity," New England Journal of Medicine 303(3): 130-135.

Gavrilov, Leonid A. and Natalia S. Gavrilova. 1991. The Biology of Life Span: A Quantitative Approach. V. P. Skulachev (ed.). Chur, Switzerland: Harwood Academic Publishers.

Gjonca, A., C. Tomassini, B. Toson, and S. Smallwood. 2005. "Sex differences in mortality: A comparison of the United Kingdom and other developed countries," Health Statistics Quarterly 26: 6-16.

Horiuchi, Shiro and John R. Wilmoth. 1998. "Deceleration in the age pattern of mortality at older ages," Demography 35 (4): 391-412.

Human Mortality Database. 2005. Data downloaded from www.mortality.org in July 2005.

Kannisto, Väinö, Jens Lauritsen, A. Roger Thatcher, and James W. Vaupel. 1994. "Reductions in mortality at advanced ages: Several decades of evidence from 27 countries," Population and Development Review 20(4): 793-810.

Keilman, Nico. 1997. "Ex-post errors in official population forecasts in industrialized countries," Journal of Official Statistics (Statistics Sweden) 13: 245-277.

Keyfitz, Nathan. 1991. "Experiments in the projection of mortality," Canadian Studies in Population 18(2): 1-17.

Lee, Ronald D. 1998. "Probabilistic approaches to population forecasting," in Wolfgang Lutz, James W. Vaupel, and Dennis A. Ahlburg (eds.), Frontiers of Population Forecasting. New York: Population Council, Supplement to Population and Development Review, Vol. 24, pp. 156-190.

- 2000. "Long-term population projections and the US Social Security System," Population and Development Review 26 (1): 137-143.

- 2003. "Rethinking the evolutionary theory of aging: Transfers, not births, shape senescence in social species," Proceedings of the National Academy of Sciences 100 (16): 9637-9642.

Lee, Ronald D. and Lawrence R. Carter. 1992. "Modeling and forecasting U.S. mortality," Journal of the American Statistical Association 87(419): 659-671.

Makeham. W. M. 1860. "On the law of mortality and the construction of annuity tables," Journal of the Institute of Actuaries 6: 301-310. 
Manton, Kenneth G., Eric Stallard, and H. Dennis Tolley. 1991. "Limits to human life expectancy: Evidence, prospects, and implications," Population and Development Review 17(4): 603-637.

National Research Council. 2000. Beyond Six Billion: Forecasting the World's Population. John Bongaarts and Rodolfo A. Bulatao (eds.). Washington, DC: National Research Council.

OECD. 2005. OECD Health Data, June 2005. Estimates of life expectancy for 2000 downloaded from OECD database www.oecd.org/document/16/0,2340,en_2825_ 495642_2085200_1_1_1_1,00.html.

Oeppen, Jim and James W. Vaupel. 2002. "Broken limits to life expectancy," Science 296: 1029-1031.

Olshansky, S. Jay and Bruce A. Carnes. 2001. The Quest for Immortality: Science at the Frontiers of Aging. New York: W.W. Norton.

Olshansky, S. Jay, Bruce A. Carnes, and Jacob Brody. 2002. "A biodemographic interpretation of life span," Population and Development Review 28(3): 501-513.

Olshansky, S. Jay, Bruce A. Carnes, and Christine Cassel. 1990. "In search of Methuselah: Estimating the upper limits to human longevity," Science 250: 634640.

Olshansky, S. Jay et al. 2005. "A potential decline in life expectancy in the United States in the 21st century," New England Journal of Medicine 352(11): 1138-1145.

Pampel, Fred C. 2002. "Cigarette use and the narrowing sex differential in mortality," Population and Development Review 28(1): 77-104.

Peto Richard, Alan D. Lopez, Jillian Boreham, Michael Thun, and Clark Heath Jr. 1992. "Mortality from tobacco in developed countries: Indirect estimation from national vital statistics," Lancet 339:1268-1278.

. 1994. Mortality from Smoking in Developed Countries 1950-2000. Oxford: Oxford University Press.

Peto, Richard, Alan D. Lopez, Jillian Boreham, and Michael Thun. 2005. Mortality from Smoking in Developed Countries 1950-2000 (2nd edition). Oxford: Oxford University Press. (data available at http://rum.ctsu.ox.ac.uk/ tobacco/)

Pollard, J. H. 1987. "Projection of age-specific mortality rates," Population Bulletin of the United Nations. Nos. 21-22. New York: United Nations, pp. 55-69. 
Preston, Samuel H. and Haidong Wang. 2006. "Sex mortality differentials in the United States: The role of cohort smoking patterns," forthcoming in Demography.

Riley, James C. 2001. Rising Life Expectancy: A Global History. New York: Cambridge University Press.

Rogers, Richard G., Robert A. Hummer, Patrick M. Krueger, and Fred C. Pampel. 2005. "Mortality attributable to cigarette smoking in the United States," Population and Development Review 31(2): 259-292.

Tabeau, Ewa, A. van den Berg Jeths, and C. R. Heathcote. 2001. Forecasting Mortality in Developed Countries. Dordrecht, Netherlands: Kluwer Academic Publishers.

Taylor, Donald H., Vic Hasselblad, Jane Henley, Michael J. Thun, and Frank A. Sloan. 2002. "Benefits of smoking cessation for longevity," American Journal of Public Health 92: 990-996.

Technical Panel on Assumptions and Methods. 2003. Report to the Social Security Advisory Board. Washington, DC. www.ssab.gov/documents/2003TechnicalPanel Rept_000.pdf

Thatcher, A. R. 1999. "The long-term pattern of adult mortality and the highest attained age," Journal of the Royal Statistical Society 162 (Part 1): 5-43.

Thatcher A. R., Väinö Kannisto, and James W. Vaupel. 1998. The Force of Mortality at Ages 80 to 120. Odense: Odense University Press.

Thun, Michael J. et al. 1998. "Trends in tobacco smoking and mortality from cigarette use in cancer prevention studies I (1959 through 1965) and II (1982 through 1988)," in D. M. Burns, L. Garfinkel, and J. Samet (eds.), Changes in CigaretteRelated Disease Risks and Their Implication for Prevention and Control. Smoking and Tobacco Control Monograph No. 8. Bethesda, MD: National Cancer Institute, US National Institutes of Health, pp. 305-382.

Tuljapurkar, S., N. Li, and C. Boe. 2000. "A universal pattern of mortality decline in the G7 countries," Nature 405: 789-792 (letter).

United Nations. 2005. World Population Prospects: The 2004 Revision. New York: United Nations.

Vaupel, J. W. 1986. "How change in age-specific mortality affects life expectancy," Population Studies 40: 147-157. 
Valkonen, T. and F. von Poppel. 1997. "The contribution of smoking to sex differences in life expectancy: Four Nordic countries and the Netherlands, 1970-1989," European Journal of Public Health 7: 163-173.

White, Kevin M. 2002. "Longevity advances in high-income countries, 1955-96," Population and Development Review 28(1): 59-76.

Wilmoth, John R. 1997. "In search of limits," in Kenneth W. Wachter and Caleb E. Finch (eds.), Between Zeus and the Salmon: The Biodemography of Longevity. Committee on Population, National Research Council. Washington, DC: National Academy Press, pp. 38-64.

- 2001. "How long can we live?" A review essay on S. Jay Olshansky and Bruce A. Carnes, The Quest for Immortality: Science at the Frontiers of Aging, Population and Development Review 27(4): 791-800.

- 2005. "Some methodological issues in mortality projection, based on an analysis of the U.S. social security system," Genus 61(1):179-212. 
Table 1 Estimates of life expectancy at birth, life expectancy without juvenile mortality, and senescent life expectancy: Averages for Denmark, England and Wales, Netherlands, Norway, and Sweden, 1850-2000

\begin{tabular}{|c|c|c|c|c|c|c|c|c|}
\hline \multirow[b]{2}{*}{ FEMALES } & \multicolumn{4}{|l|}{ Year } & \multicolumn{4}{|l|}{ Trend } \\
\hline & 1850 & 1900 & 1950 & 2000 & $\begin{array}{c}1850- \\
1900\end{array}$ & $\begin{array}{c}1900- \\
1950\end{array}$ & $\begin{array}{c}1950- \\
2000\end{array}$ & $\begin{array}{c}1850- \\
2000\end{array}$ \\
\hline Life expectancy at birth, $L E$ & 45.7 & 52.1 & 72.2 & 80.7 & 6.4 & 20.1 & 8.5 & 35.0 \\
\hline$L E$ without juvenile mortality, $L E_{J}$ & 63.9 & 66.6 & 75.0 & 81.4 & 2.7 & 8.3 & 6.4 & 17.5 \\
\hline Senescent life expectancy, $L E_{S}$ & 72.3 & 73.2 & 76.0 & 81.7 & 1.0 & 2.8 & 5.6 & 9.4 \\
\hline Juvenile mortality effect, $J$ & 18.2 & 14.5 & 2.7 & 0.6 & -3.7 & -11.8 & -2.1 & -17.5 \\
\hline Background mortality effect, $B$ & 8.4 & 6.6 & 1.1 & 0.3 & -1.8 & -5.5 & -0.8 & -8.1 \\
\hline MALES & & & & & & & & \\
\hline Life expectancy at birth, $L E$ & 42.6 & 48.9 & 69.1 & 75.8 & 6.3 & 20.3 & 6.7 & 33.2 \\
\hline$L E$ without juvenile mortality, $L E_{J}$ & 62.0 & 64.6 & 72.8 & 76.8 & 2.6 & 8.1 & 4.0 & 14.8 \\
\hline Senescent life expectancy, $L E_{S}$ & 69.5 & 71.2 & 74.0 & 77.6 & 1.7 & 2.8 & 3.5 & 8.0 \\
\hline Juvenile mortality effect, $J$ & 19.4 & 15.7 & 3.6 & 1.0 & -3.7 & -12.1 & -2.6 & -18.5 \\
\hline Background mortality effect, $B$ & 7.5 & 6.6 & 1.2 & 0.8 & -0.9 & -5.4 & -0.5 & -6.7 \\
\hline
\end{tabular}

Table 2 Senescent life expectancy, with and without smoking: Average for 16 countries, 1950-2000

\begin{tabular}{lccc}
\hline & 1950 & 2000 & $1950-2000$ \\
\cline { 2 - 4 } FEMALES & 75.6 & 82.7 & 7.2 \\
With smoking $\left(L E_{S}\right)$ & 75.6 & 83.8 & 8.2 \\
Without smoking $\left(L E_{N S}\right)$ & 0.0 & 1.0 & 1.0 \\
Smoking effect $(S)$ & & & \\
MALES & 72.2 & 77.8 & 5.6 \\
With smoking $\left(L E_{S}\right)$ & 73.3 & 80.2 & 6.9 \\
Without smoking $\left(L E_{N S}\right)$ & 1.1 & 2.4 & 1.3 \\
Smoking effect $(S)$ & &
\end{tabular}




\begin{tabular}{|c|c|c|c|c|c|c|}
\hline \multirow[b]{2}{*}{ FEMALES } & \multicolumn{3}{|c|}{$\begin{array}{l}\text { Senescent life expectancy, no } \\
\text { smoking }\left(L E_{N S}\right)\end{array}$} & \multicolumn{3}{|c|}{ Smoking effect $(S)$} \\
\hline & 1950 & 2000 & $1950-2000$ & 1950 & 2000 & $1950-2000$ \\
\hline Austria & 74.9 & 82.8 & 7.9 & 0.1 & 0.5 & 0.4 \\
\hline Belgium & 75.1 & 82.8 & 7.7 & 0.0 & 0.5 & 0.5 \\
\hline Canada & 75.6 & 85.1 & 9.5 & 0.0 & 2.1 & 2.1 \\
\hline Denmark & 75.3 & 82.4 & 7.1 & 0.0 & 2.4 & 2.4 \\
\hline England \& Wales & 76.0 & 83.0 & 7.0 & 0.3 & 1.8 & 1.5 \\
\hline Finland & 74.5 & 82.7 & 8.2 & 0.0 & 0.4 & 0.4 \\
\hline France & 75.9 & 84.5 & 8.5 & 0.0 & 0.3 & 0.3 \\
\hline Italy & 75.9 & 84.1 & 8.1 & 0.0 & 0.5 & 0.5 \\
\hline Japan & 74.4 & 86.3 & 11.9 & 0.0 & 0.5 & 0.5 \\
\hline Netherlands & 76.2 & 83.0 & 6.8 & 0.0 & 1.1 & 1.1 \\
\hline New Zealand & 75.8 & 84.2 & 8.4 & 0.0 & 1.5 & 1.5 \\
\hline Norway & 77.3 & 83.5 & 6.2 & 0.0 & 1.0 & 1.0 \\
\hline Spain & 75.9 & 84.1 & 8.2 & 0.0 & 0.0 & 0.0 \\
\hline Sweden & 75.7 & 83.6 & 7.9 & 0.0 & 0.8 & 0.8 \\
\hline Switzerland & 75.4 & 84.4 & 9.0 & 0.0 & 0.5 & 0.5 \\
\hline United States & 75.2 & 83.6 & 8.4 & 0.0 & 2.5 & 2.5 \\
\hline All & 75.6 & 83.8 & 8.2 & 0.0 & 1.0 & 1.0 \\
\hline \multicolumn{7}{|l|}{ MALES } \\
\hline Austria & 73.4 & 79.0 & 5.6 & 2.5 & 2.2 & -0.2 \\
\hline Belgium & 72.8 & 80.6 & 7.8 & 1.6 & 3.7 & 2.1 \\
\hline Canada & 73.2 & 81.6 & 8.4 & 0.9 & 2.7 & 1.7 \\
\hline Denmark & 74.9 & 78.8 & 3.9 & 0.8 & 2.8 & 2.1 \\
\hline England \& Wales & 73.8 & 79.6 & 5.8 & 2.8 & 2.4 & -0.4 \\
\hline Finland & 71.9 & 78.2 & 6.3 & 2.5 & 1.9 & -0.7 \\
\hline France & 71.5 & 80.0 & 8.5 & 0.7 & 2.6 & 1.9 \\
\hline Italy & 73.7 & 81.3 & 7.6 & 0.5 & 2.7 & 2.2 \\
\hline Japan & 70.6 & 81.1 & 10.5 & 0.0 & 1.9 & 1.9 \\
\hline Netherlands & 76.4 & 80.2 & 3.8 & 1.4 & 3.0 & 1.7 \\
\hline New Zealand & 73.3 & 81.0 & 7.7 & 1.0 & 2.1 & 1.1 \\
\hline Norway & 75.6 & 80.1 & 4.5 & 0.1 & 1.7 & 1.6 \\
\hline Spain & 72.2 & 80.9 & 8.7 & 0.4 & 2.9 & 2.5 \\
\hline Sweden & 74.6 & 80.0 & 5.4 & 0.3 & 1.1 & 0.8 \\
\hline Switzerland & 73.4 & 81.1 & 7.7 & 1.4 & 1.9 & 0.6 \\
\hline United States & 71.6 & 79.7 & 8.2 & 1.3 & 3.0 & 1.6 \\
\hline All & 73.3 & 80.2 & 6.9 & 1.1 & 2.4 & 1.3 \\
\hline
\end{tabular}




\begin{tabular}{|c|c|c|c|c|}
\hline \multirow[b]{2}{*}{ FEMALES } & \multicolumn{2}{|c|}{ Observed $(L E)$} & \multicolumn{2}{|c|}{ Projections to 2050} \\
\hline & 1950 & 2000 & $\begin{array}{c}\text { New method } \\
(\text { constant } J, B, S)\end{array}$ & UN \\
\hline Austria & 67.4 & 81.1 & 88.6 & 87.4 \\
\hline Belgium & 68.9 & 80.9 & 88.5 & 86.9 \\
\hline Canada & 70.6 & 81.9 & 89.4 & 87.9 \\
\hline Denmark & 71.5 & 79.1 & 86.7 & 84.8 \\
\hline England \& Wales & 71.3 & 80.2 & 87.7 & 85.7 \\
\hline Finland & 67.9 & 81.0 & 88.6 & 87.4 \\
\hline France & 69.2 & 82.8 & 90.3 & 88.3 \\
\hline Italy & 67.5 & 82.5 & 90.0 & 88.4 \\
\hline Japan & 60.9 & 84.6 & 92.1 & 92.7 \\
\hline Netherlands & 72.6 & 80.8 & 88.4 & 86.0 \\
\hline New Zealand & 71.2 & 81.3 & 88.8 & 86.6 \\
\hline Norway & 73.3 & 81.4 & 88.9 & 87.5 \\
\hline Spain & 64.3 & 82.7 & 90.2 & 88.6 \\
\hline Sweden & 72.4 & 82.0 & 89.6 & 87.9 \\
\hline Switzerland & 71.1 & 82.6 & 90.2 & 88.6 \\
\hline United States & 71.1 & 79.5 & 87.0 & 85.2 \\
\hline All & 69.5 & 81.5 & 89.1 & 87.5 \\
\hline \multicolumn{5}{|l|}{ MALES } \\
\hline Austria & 62.3 & 75.1 & 82.6 & 83.0 \\
\hline Belgium & 63.9 & 74.6 & 82.1 & 81.3 \\
\hline Canada & 66.2 & 76.7 & 84.2 & 83.3 \\
\hline Denmark & 69.1 & 74.4 & 82.0 & 80.3 \\
\hline England \& Wales & 66.5 & 75.5 & 83.0 & 81.8 \\
\hline Finland & 60.4 & 74.2 & 81.7 & 82.5 \\
\hline France & 63.5 & 75.3 & 82.8 & 81.8 \\
\hline Italy & 64.1 & 76.6 & 84.1 & 82.5 \\
\hline Japan & 57.6 & 77.7 & 85.2 & 84.4 \\
\hline Netherlands & 70.3 & 75.7 & 83.3 & 80.8 \\
\hline New Zealand & 67.4 & 76.1 & 83.7 & 82.7 \\
\hline Norway & 69.9 & 75.9 & 83.5 & 83.0 \\
\hline Spain & 59.4 & 75.8 & 83.3 & 81.7 \\
\hline Sweden & 69.8 & 77.4 & 84.9 & 83.6 \\
\hline Switzerland & 66.7 & 76.9 & 84.5 & 83.1 \\
\hline United States & 65.6 & 74.1 & 81.6 & 80.2 \\
\hline All & 65.2 & 75.8 & 83.3 & 82.2 \\
\hline
\end{tabular}


Figure 1 Life expectancy at birth for females and males in 16 high-income countries, 1850-2000
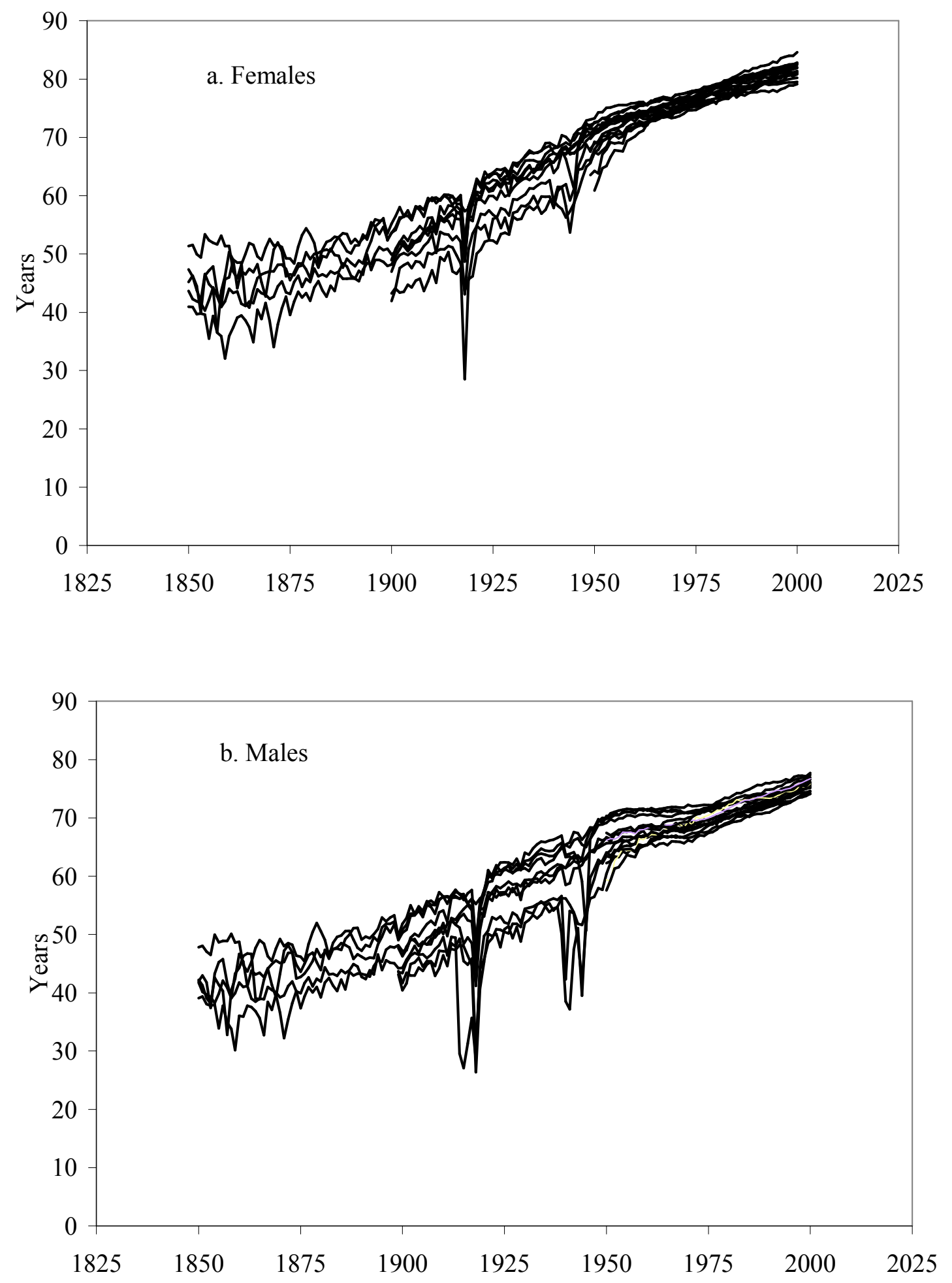

Source: Human Mortality Database (2005) 
Figure 2 Three longevity measures, 1850-2000, averages for Denmark, England and Wales, Netherlands, Norway, and Sweden
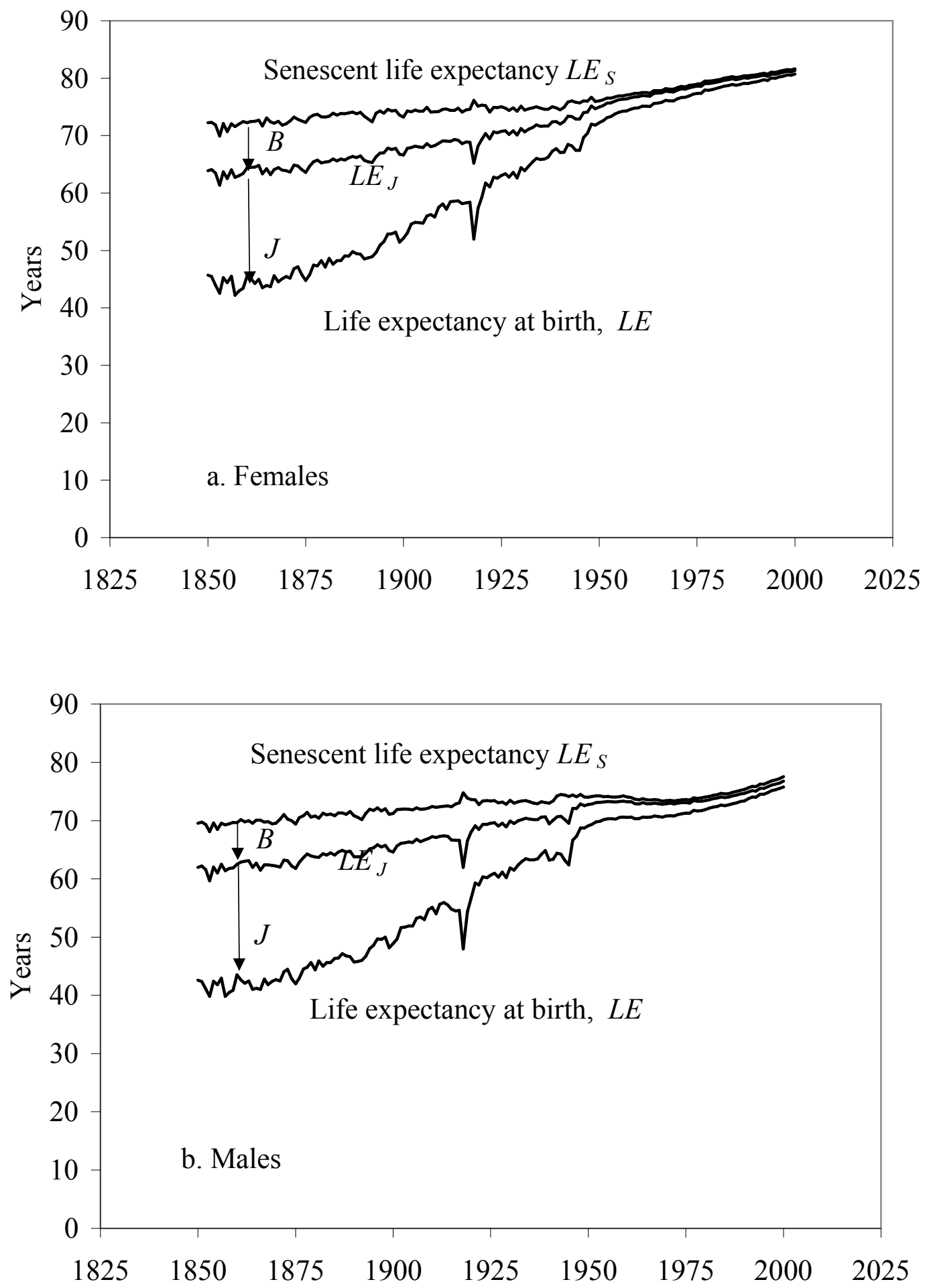

Source: Human Mortality Database (2005) and estimates by author. 
Figure 3 Juvenile mortality effect on life expectancy, averages for Denmark, England and Wales, Netherlands, Norway, and Sweden

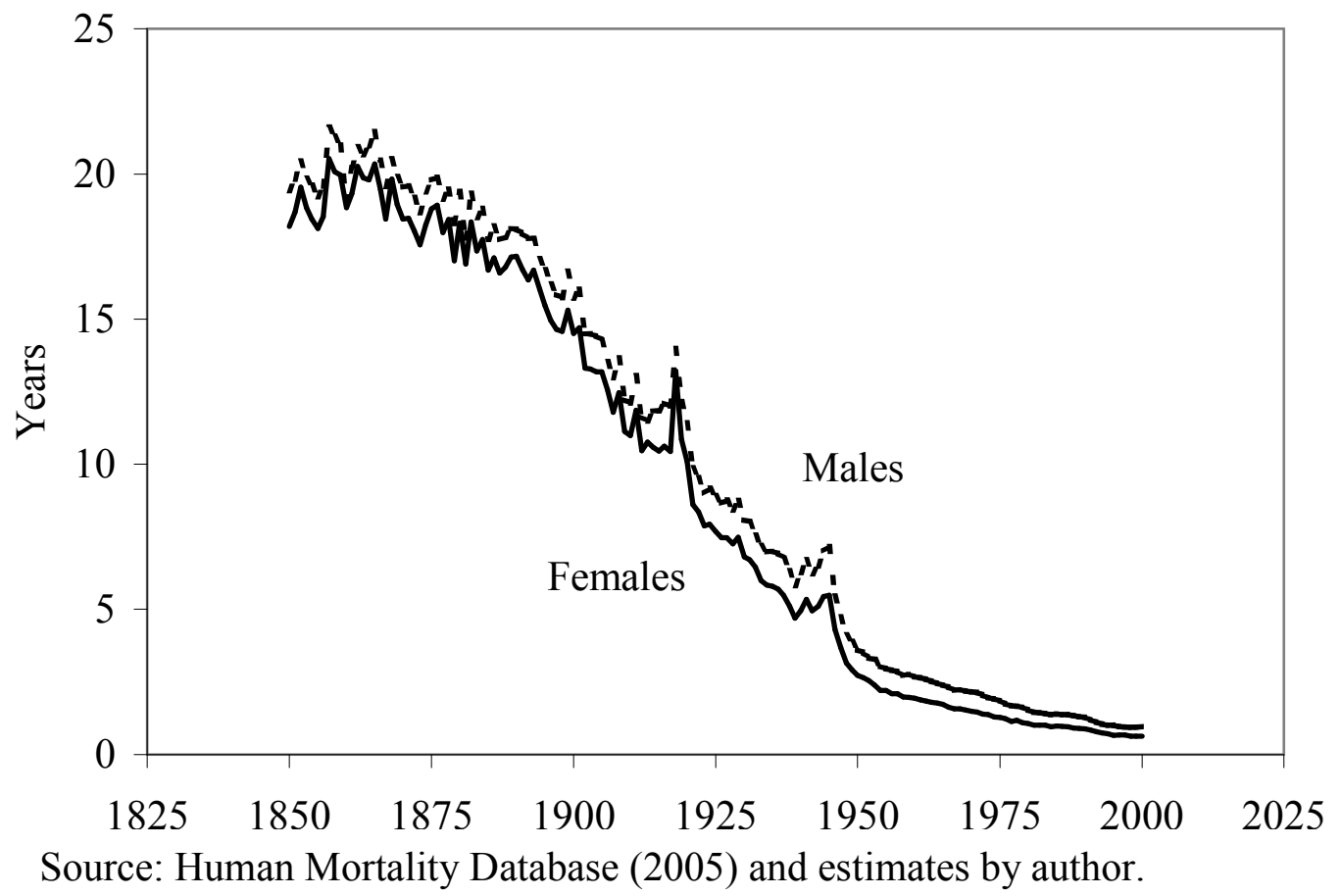

Figure 4 Background mortality effect on life expectancy, averages for Denmark, England and Wales, Netherlands, Norway, and Sweden

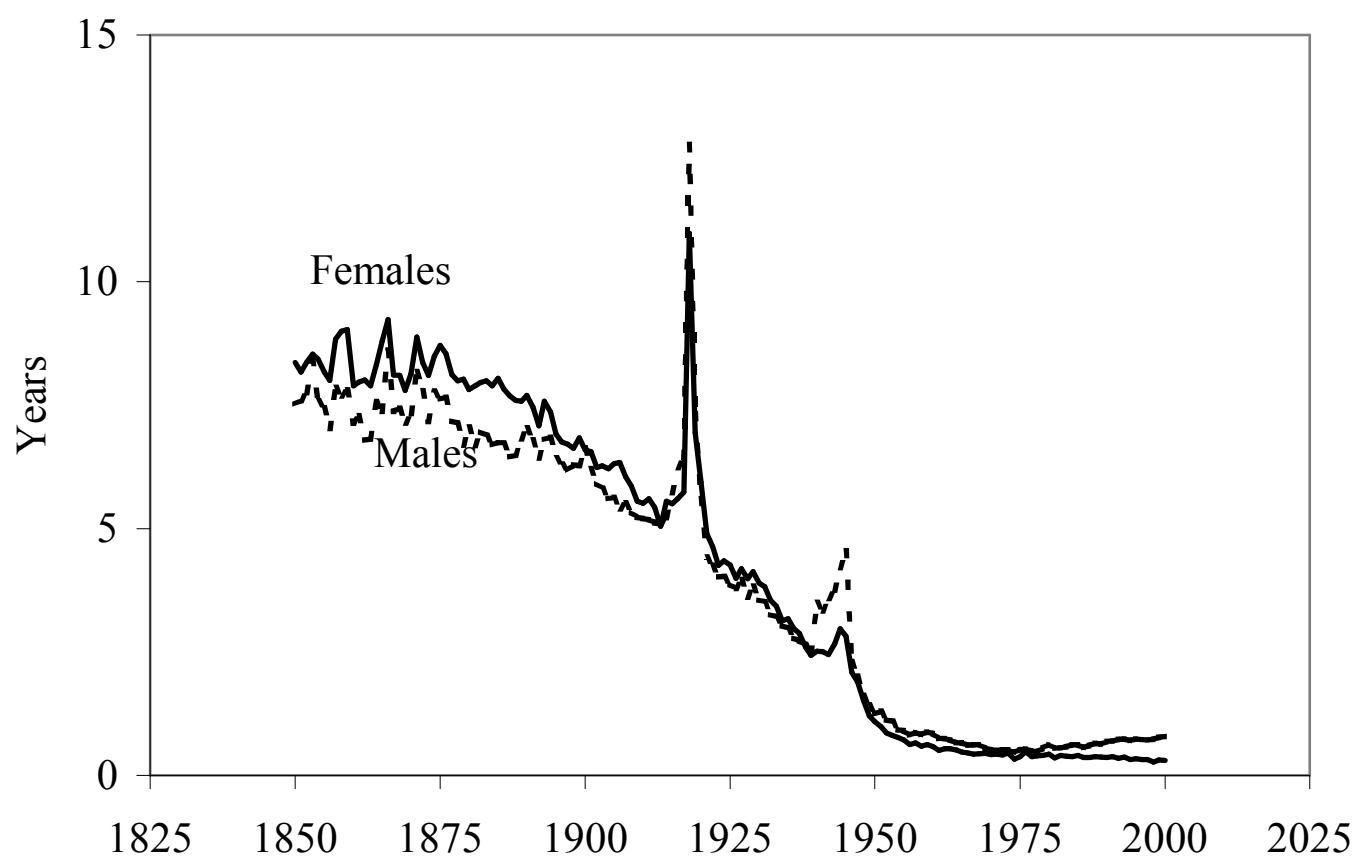

Source: Human Mortality Database (2005) and estimates by author. 
Figure 5 Decomposition of changes in female life expectancy at birth for Denmark, England and Wales, Netherlands, Norway, and Sweden, 18501900, 1900-1950, and 1950-2000

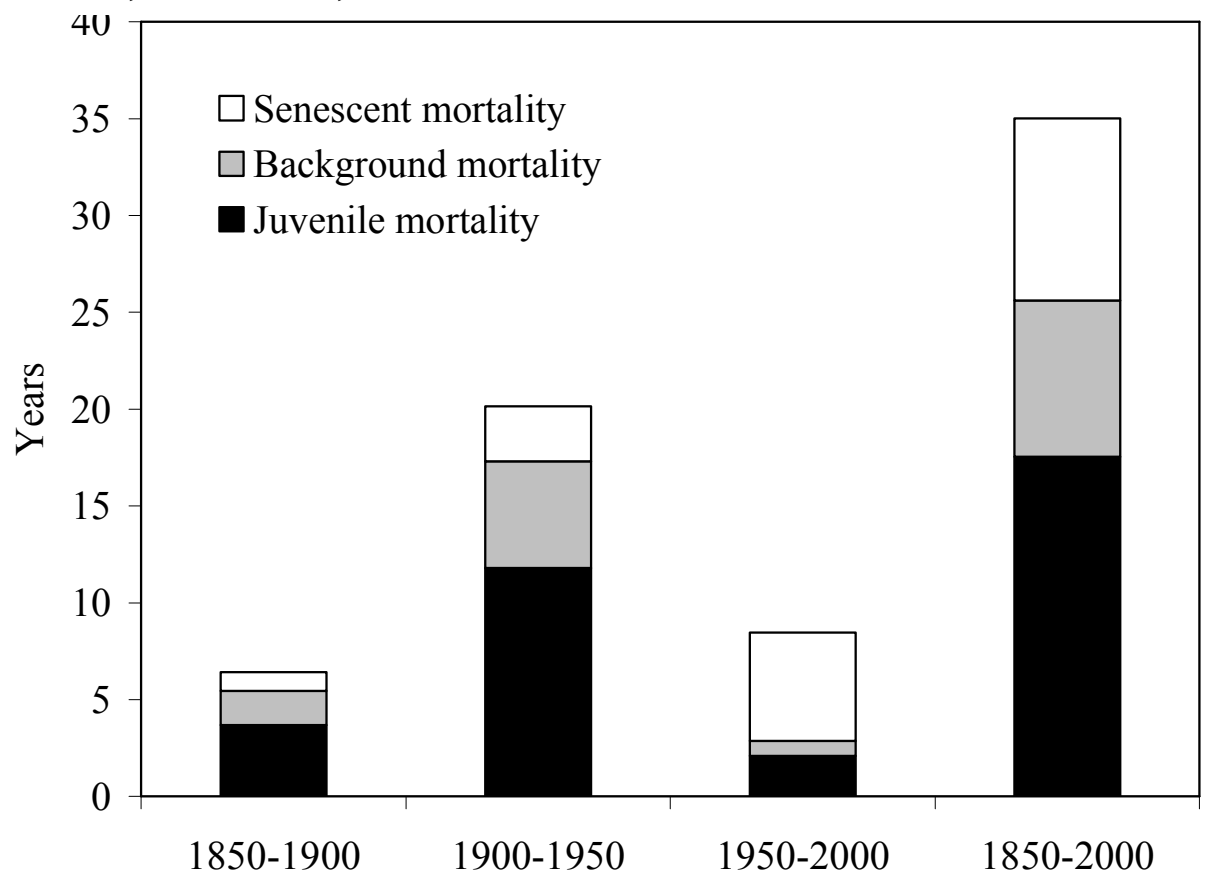

Figure 6 Proportion of all deaths attributed to smoking in the developed world

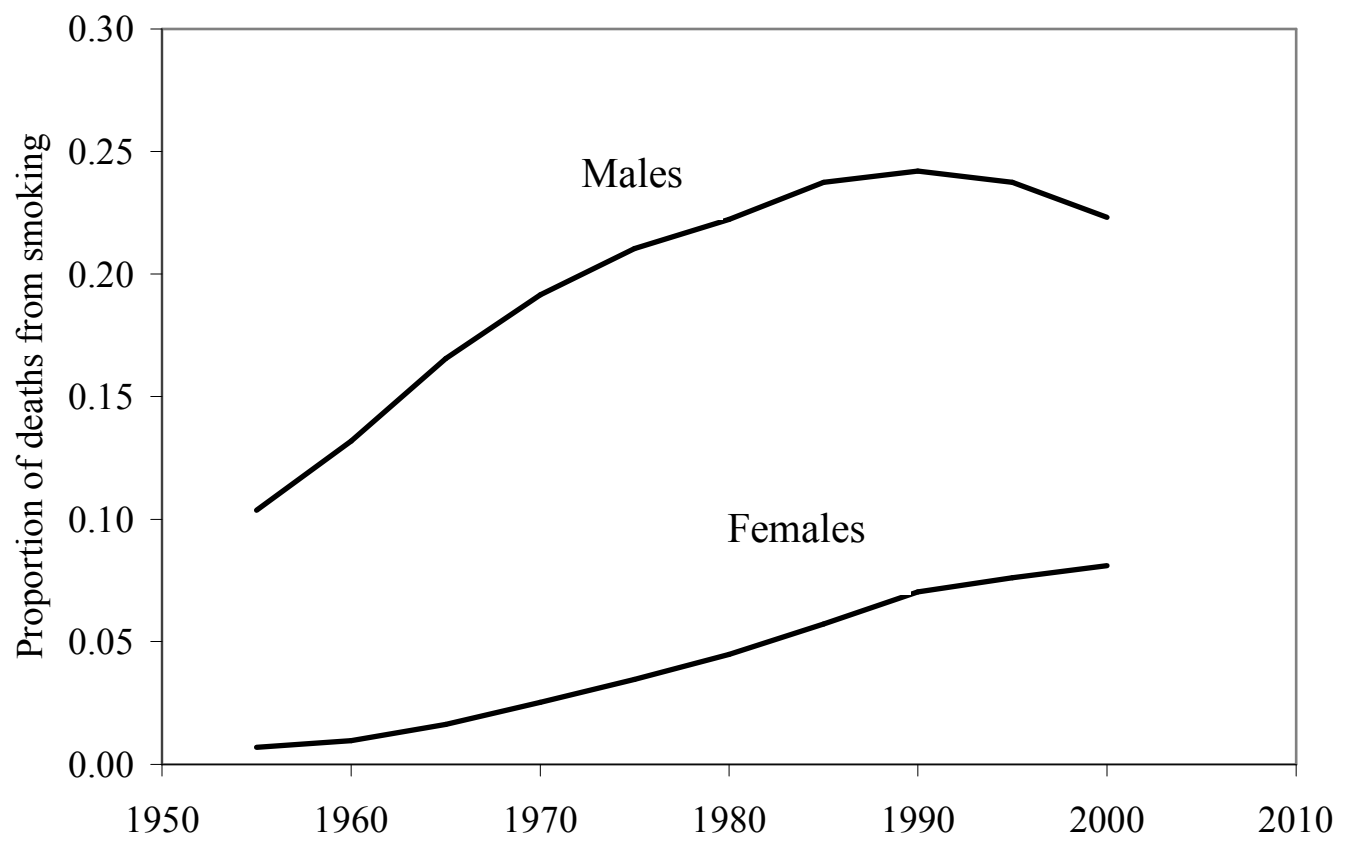

Source: Peto et al. (2005). 
Figure 7 Senescent life expectancy with and without smoking, average for 16 countries

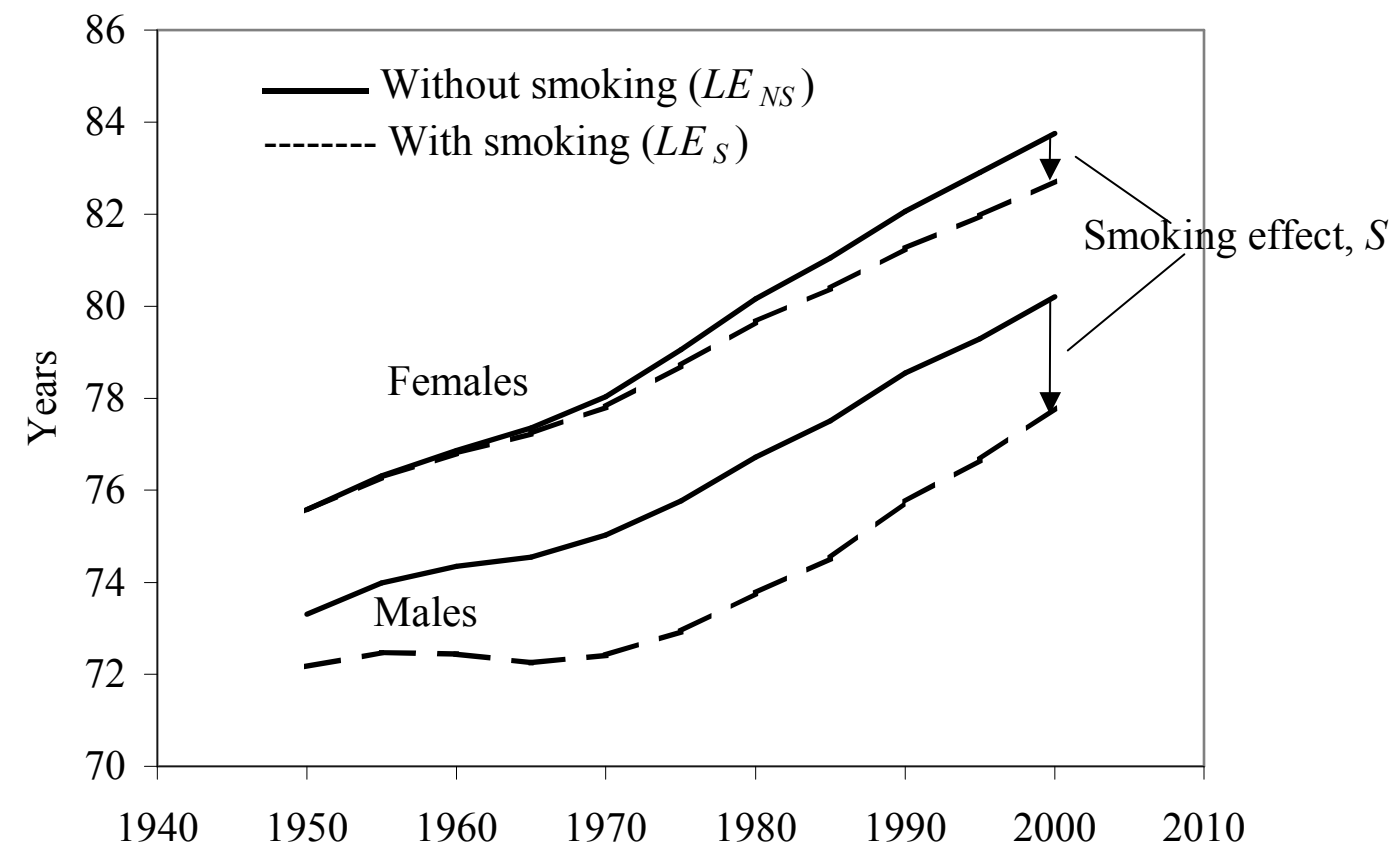

Figure 8 Senescent life expectancy without smoking in 16 countries, 1950-2000

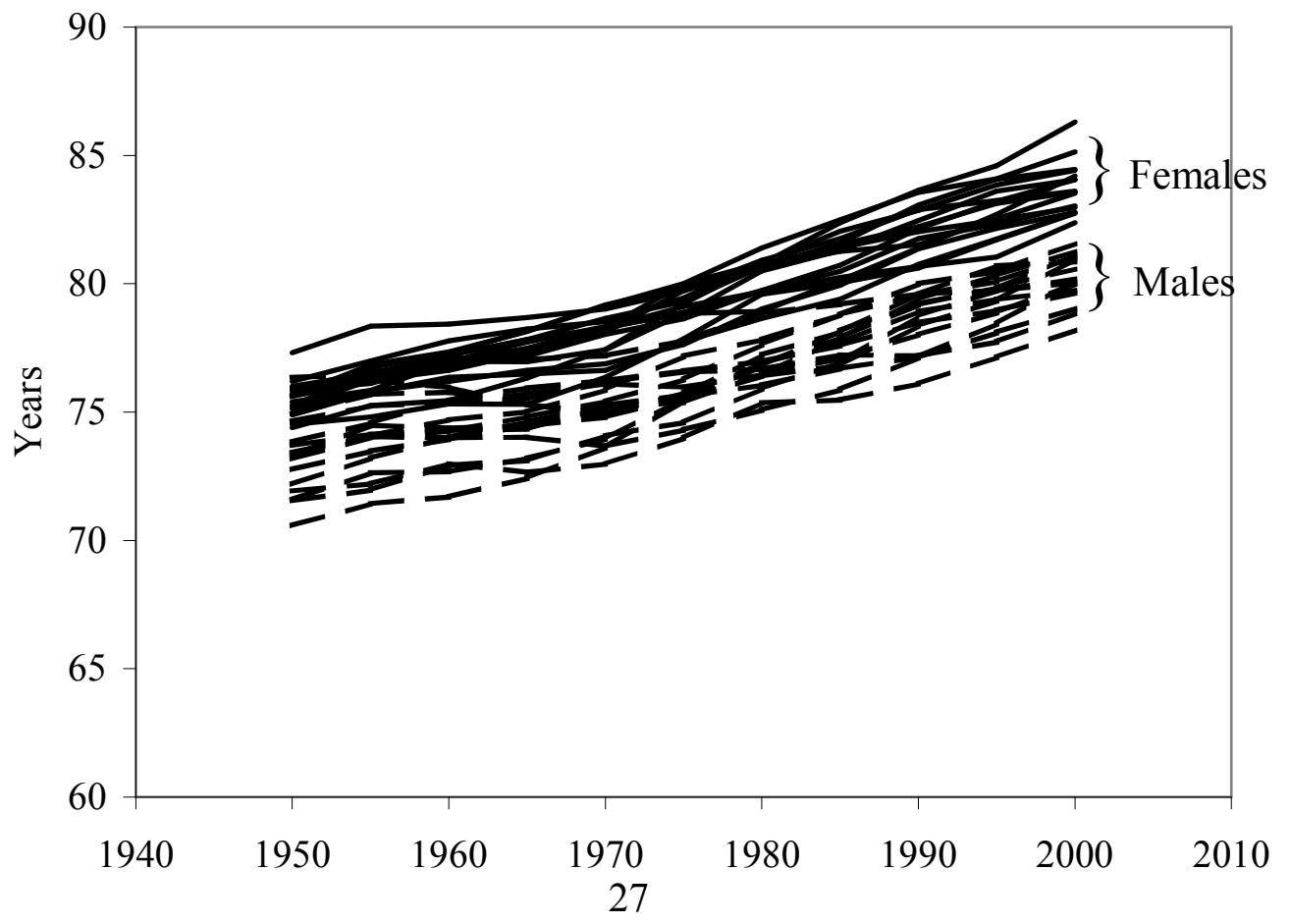


Figure 9 Alternative projections to 2050 of life expectancy at birth for US females

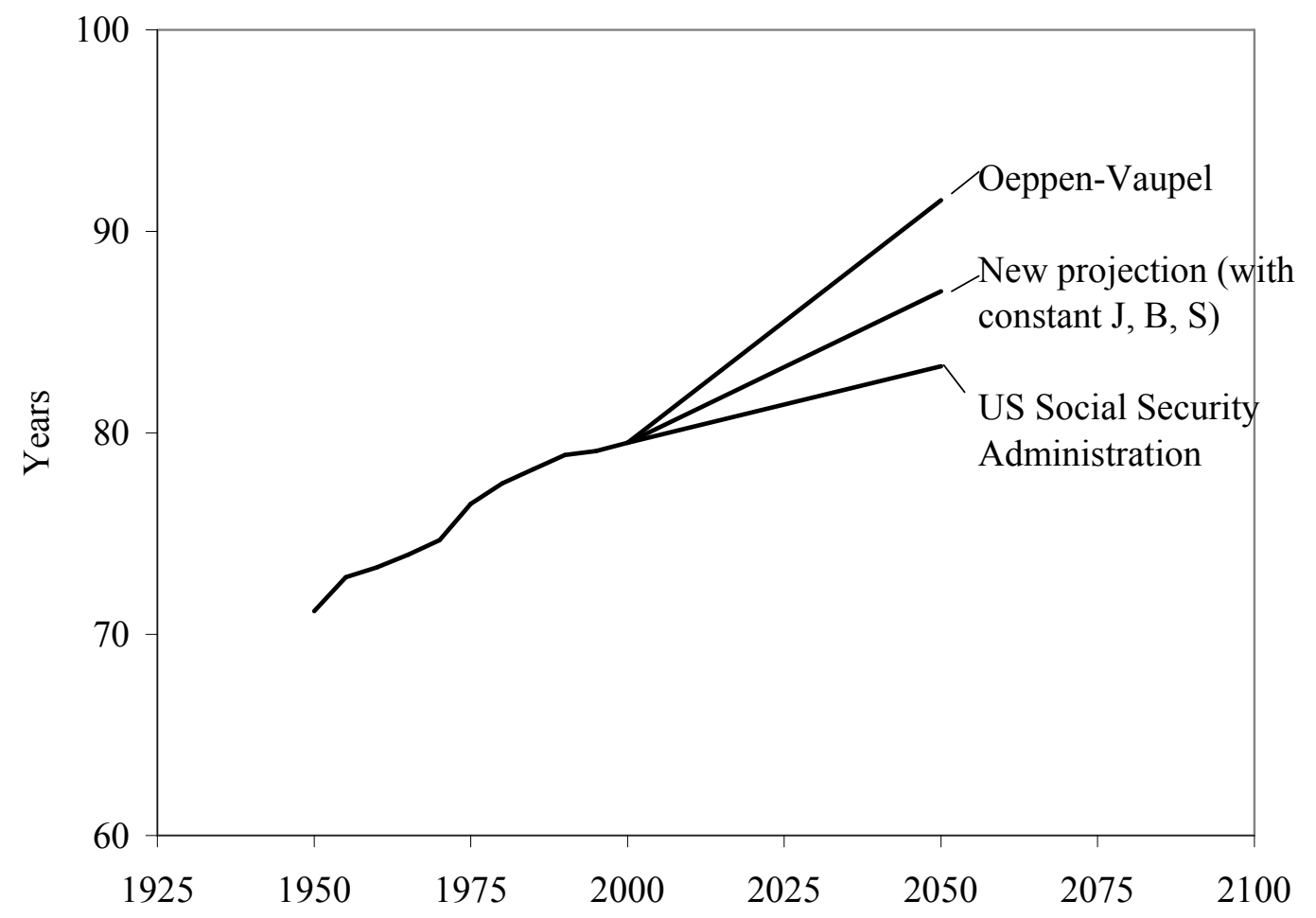

Source: Board of Trustees of OASDI Trust Funds 2005; Oeppen and Vaupel 2002; estimates by author 


\section{POLICY RESEARCH DIVISION WORKING PAPERS}

If still in print, single copies of up to three working papers from 1989 through 2003 are available free of charge.

Beginning with the 2004 issues, working papers are no longer available in print format. Instead they are distributed electronically. As each new paper is completed subscribers are notified by e-mail and a link to the paper is provided.

To subscribe to the Policy Research Division working paper e-mail notification list, or to obtain back issues from 1989 to 2003, please send your request to prdwp@popcouncil.org.

PDFs of recent issues are available at www.popcouncil.org/publications/wp/prd/rdwplist.html

2006

215 John Bongaarts, "How long will we live?"

214 Zachary Zimmer, Toshiko Kaneda, and Laura Spess, "Urban versus rural mortality among older adults in China."

213 Paul Demeny and Geoffrey McNicoll, "The political demography of the world system, 2000-2050."

212 Monica Grant and Kelly Hallman, "Pregnancy-related school dropout and prior school performance in South Africa."

211 Kelly Hallman, Sara Peracca, Jennifer Catino, and Marta Julia Ruiz, "Multiple disadvantages of Mayan females: The effect of gender, ethnicity, poverty, and residence on education in Guatemala."

210 Geoffrey McNicoll, "Policy lessons of the East Asian demographic transition."
209 Cynthia B. Lloyd, Cem Mete, and Monica J. Grant, "The implications of changing educational and family circumstances for children's grade progression in rural Pakistan: 1997-2004."

2005

208 James F. Phillips, Ayaga A. Bawah, and Fred N. Binka, "Accelerating reproductive and child health program development: The Navrongo Initiative in Ghana."

207 John Bongaarts and Griffith Feeney, "The quantum and tempo of life-cycle events."

206 Barbara S. Mensch, Monica J. Grant, and Ann K. Blanc, "The changing context of sexual initiation in sub-Saharan Africa."

205 Geoffrey McNicoll, "Population and sustainability."

204 John Bongaarts, "The causes of stalling fertility transitions." 
Binka, "How many years of life could be saved if malaria were eliminated from a hyperendemic area of northern Ghana?"

202 Barbara S. Mensch, Susheela Singh, and John B. Casterline, "Trends in the timing of first marriage among men and women in the developing world."

201 Zachary Zimmer, "Active life expectancy and functional limitations among older Cambodians: Results from a 2004 survey."

200 Brian Wells Pence, Philomena Nyarko, James F. Phillips, and Cornelius Debpuur, "The effect of community nurses and health volunteers on child mortality: The Navrongo Community Health and Family Planning Project."

199 Zachary Zimmer, Linda G. Martin, Mary Beth Ofstedal, and Yi-Li Chuang, "Education of adult children and mortality of their elderly parents in Taiwan."

198 Mian Bazle Hossain, James F. Phillips, and Thomas K. LeGrand, "The impact of childhood mortality on fertility in six rural thanas of Bangladesh."

197 Kristine R. Baker, Mary Beth Ofstedal, Zachary Zimmer, Zhe Tang, and Yi-Li Chuang, "Reciprocal effects of health and economic well-being among older adults in Taiwan and Beijing."

196 Mark R. Montgomery and Paul C. Hewett, 'Poverty and children's schooling in urban and rural Senegal."

195 Luciana Suran, Sajeda Amin, Lopita Huq, and Kobita Chowdury, "Does dowry improve life for brides? A test of the bequest theory of dowry in rural Bangadesh."

194 Barbara S. Mensch, Monica J. Grant, Mary P. Sebastian, Paul C. Hewett, and Dale Huntington. "The effect of a livelihoods intervention in an urban slum in India: Do vocational counseling and training alter the attitudes and behavior of adolescent girls?"

93 Amanda Ritchie, Cynthia B. Lloyd, and Monica Grant. "Gender differences in time use among adolescents in developing countries: Implications of rising school enrollment rates."

192 John Bongaarts. "Long-range trends in adult mortality: Models and projection methods."

191 John Koku Awoonor-Williams, Ellie S. Feinglass, Rachel Tobey, Maya N. Vaughan-Smith, Frank K. Nyonator, Tanya C. Jones, and James F. Phillips, "Bridging the gap between evidence-based innovation and national healthsector reform in Ghana."

190 Kelly Hallman, "Socioeconomic disadvantage and unsafe sexual behaviors among young women and men in South Africa."

189 Toshiko Kaneda, Zachary Zimmer, and Zhe Tang, "Differentials in life expectancy and active life expectancy by socioeconomic status among older adults in Beijing." 
188 Cynthia B. Lloyd and Monica J.

Grant, "Growing up in Pakistan:

The separate experiences of males and females."

187 Zachary Zimmer, Xianghua Fang, Toshiko Kaneda, Zhe Tang, and Julia Kwong. "Trends and transitions in children's coresidence with older adults in Beijing municipality."

186 Sajeda Amin and Alaka M. Basu. "Popular perceptions of emerging influences on mortality and longevity in Bangladesh and West Bengal."

185 John Bongaarts. "Population aging and the rising cost of public pensions."

184 Mark R. Montgomery and Paul C. Hewett. "Urban poverty and health in developing countries: Household and neighborhood effects." 